\title{
5MHz PWM-Controlled Current-Mode Resonant DC-DC Converter Using GaN-FETs
}

\author{
Akinori Hariya/Nagasaki University \\ Graduate School of Engineering \\ Nagasaki Univ. \\ Nagasaki, Japan \\ bb52312202@cc.nagasaki-u.ac.jp
}

\author{
Hiroshige Yanagi / TDK-Lambda Corporation \\ Advanced Development Dept. \\ TDK-Lambda \\ Nigata, Japan \\ yanagi@jp.tdk-lambda.com
}

\author{
Yoichi Ishizuka/Nagasaki University \\ Graduate School of Engineering \\ Nagasaki Univ. \\ Nagasaki, Japan \\ isy2@nagasaki-u.ac.jp
}

\author{
Ken Matsuura/TDK-Lambda Corporation \\ Advanced Development Dept. \\ TDK-Lambda \\ Nigata, Japan \\ matsuken@jp.tdk-lambda.com
}

\author{
Satoshi Tomioka / TDK-Lambda Corporation \\ Advanced Development Dept. \\ TDK-Lambda \\ Nigata, Japan \\ s.tomioka@jp.tdk-lambda.com
}

\author{
Tamotsu Ninomiya / \\ The International Centre for the Study of \\ East Asian Development \\ Electronics Research Group for Sustainability \\ ICSEAD \\ Kitakyushu, Japan \\ t_ninomiya@icsead.or.jp
}

\begin{abstract}
In this paper, the method of the realization of a $\mathrm{MHz}$ level switching frequency DC-DC converter for high power-density is presented. For high power-density, Gallium Nitride field effect transistor (GaN-FET) and currentmode resonant DC-DC converter are adopted. In addition, the proposed pulse width modulation (PWM) control method which is suitable for the isolated current-mode resonant DC-DC converter operated at MHz level switching frequency, and the novel primary-side zero voltage switching (ZVS) turn on method for the proposed PWM control are presented.

Some experiments have been done with $5 \mathrm{MHz}$ isolated DC-DC converter which has GaN-FET, and the total volume of the circuit is $16.14 \mathrm{~cm}^{3}$. With the proposed PWM control method, input voltage range is $36-44 \mathrm{~V}$, and maximum load current range is $8 \mathrm{~A}$ at $V_{i}=44 \mathrm{~V}$. The primaryside ZVS turn on is confirmed, and the maximum powerefficiency is $89.4 \%$.
\end{abstract}

Keywords - High Switching Frequency, PWM Control, Current-Mode Resonant DC-DC Converter, GaN-FET

\section{INTRODUCTION}

Recently, high power-efficiency and high powerdensity DC-DC converters have been required in information and communication technology (ICT) equipment. Corresponding to the requirement of high power-density, the increase in the switching frequency of these converters has been considered to be one of key technologies. In particular, $\mathrm{MHz}$ level switching frequency contributes significantly to downsizing.

However, by adopting high switching frequency, power loss such as switching loss and gate driving loss increases. To solve this problem, the current-mode resonant DC-DC converter is effective because this converter can reduce switching loss. Also, GaN-FETs are suitable for high switching frequency operation as semiconductor switches because of low gate driving loss. Therefore, we have developed a $5 \mathrm{MHz}$ current-mode resonant DC-DC converter with GaN-FETs [1].

Current-mode resonant DC-DC converters are usually controlled by pulse frequency modulation (PFM). However, PFM control is hard to design to control the output voltage at $\mathrm{MHz}$ level switching frequency operation. The details are going to be described in the section III.

To solve the issue, this paper presents a novel PWM control method for the current-mode resonant DC-DC converter for $\mathrm{MHz}$ level switching frequency. This converter topology is same as the conventional currentmode resonant DC-DC converter with synchronous rectification. The feature of the converter is controlling the output voltage without any additional components. By using transformer's leakage inductance and secondary-side synchronously rectifying switches, the novel control method for boost conversion is realized.

In the previous researches, some PWM-controlled current-mode resonant DC-DC converters have been presented [2-4]. For example, the method of additional auxiliary circuits for regulating output voltage [2-3], and the method of controlling the duty ratio of primary-side switches [4] have been proposed. However, these methods need some additional components for regulating output voltage. 
On the other hand, the advantages of the proposed method are controlling secondary-side switches and no additional components.

To accomplish the primary-side ZVS turn on, small magnetizing inductance $L_{m}$ have been used in currentmode resonant DC-DC converter generally. However, small $L_{m}$ leads to increase of primary-side current which is cause of reducing power-efficiency. Therefore, to accomplish the ZVS operation in the proposed method, phase-shift between primary and secondary-side switches which control resonant current is adopted. As a result, this proposed converter maintains primary-side ZVS turn on.

The targets of the study are to obtain the high performance which is the small volume, $36-75 \mathrm{~V}$ or $42-$ $53 \mathrm{~V}$ of input voltage range, $10 \mathrm{~A}$ of maximum load current range, the realization of primary-side ZVS turn on, and high power-efficiency.

In the section II, the approach of the realization of DCDC converter operated at $\mathrm{MHz}$ level switching frequency is described. In the section III, the issue of the conventional PFM-controlled current-mode resonant DC$\mathrm{DC}$ converter in $\mathrm{MHz}$ level operation is revealed. In the section IV, the proposed PWM-controlled current-mode resonant DC-DC converter is explained. In the section V, the experimental results are revealed.

\section{THE APPROACH OF THE REALIZATION OF DC-DC CONVERTER OPERATED AT MHZ LEVEL SWITCHING FREQUENCY}

For miniaturization of the DC-DC converter, the increase in the switching frequency of these converters is considered to be one of key technologies. Therefore, this study challenges $5 \mathrm{MHz}$ of switching frequency at $120 \mathrm{~W}$ of output power. Studies that satisfy both the frequency and the output power have not been challenged so far, as shown in Fig. 1. To suppress increasing core power loss with high switching frequency, NiZn ferrite core is used in the study because this core material is suitable for high frequency operation [5]. In addition, to decrease parasitic inductance, multilayer printed circuit board (PCB) and planar transformer like [6], [7] is adopted.

However, by adopting high switching frequency, power loss such as switching loss and gate driving loss increases dramatically. The switching loss $P_{s w}$ is expressed by

$$
P_{s w}=C_{o s s} V_{D S}^{2} f_{s}
$$

where $C_{o s s}$ is output capacitance of FET, $V_{D S}$ is drainto-source voltage of FET, and $f_{s}$ is switching frequency. The gate driving loss $P_{d}$ is expressed by

$$
P_{d}=Q_{G} V_{G S} f_{s}
$$

where $Q_{G}$ is gate charge, and $V_{G S}$ is gate-to-source voltage of FET. From eqs. (1) and (2), these power losses are proportional to $f_{s}$.

For reducing gate driving loss, GaN-FET is adopted in the study because GaN-FET has low $Q_{G}$ and be driven at low gate-source voltage. From these reasons, GaN-FET can realize low $P_{d}$. Also, another researches have been

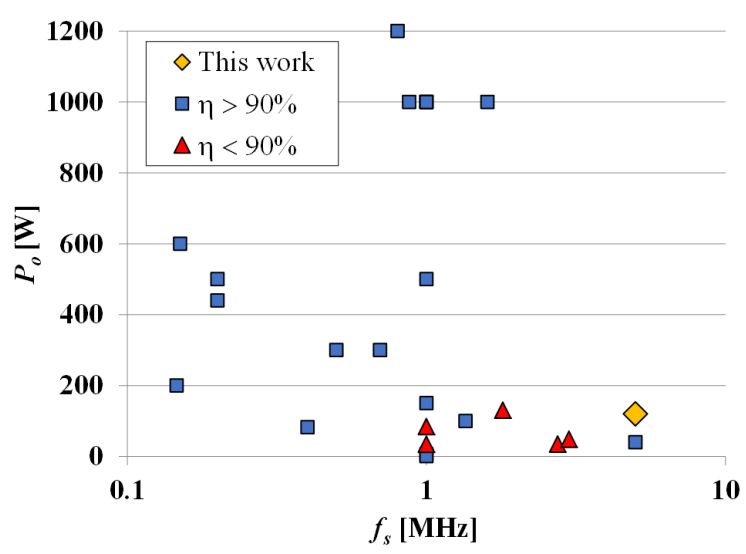

Fig. 1. The performance of isolated DC-DC converters in the previous papers.

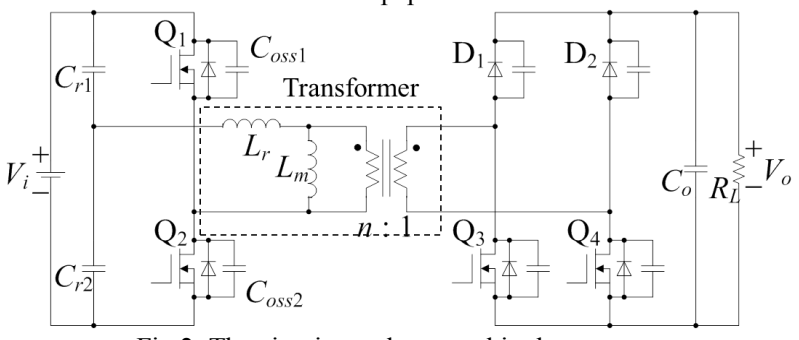

Fig 2. The circuit topology used in the paper.

proved utilizing GaN-FET for high switching frequency DC-DC converter is very practical [8-10]. Some literatures [11-13] prove that GaN devices are more effective than silicon devices.

However, because GaN-FETs have low gate-to-source threshold voltage $V_{t h}$, low maximum gate-to-source voltage $V_{G S S}$, and high source-to-drain voltage $V_{S D}$, it is difficult to drive these FETs. Therefore, suitable drive circuit for GaN-FET is needed. Some literatures show that driver LM5113 is suitable for driving GaN-FETs [14], [15].

Furthermore, current-mode resonant DC-DC converter topology featuring primary-side ZVS turn on operation is adopted because switching loss can be suppressed. The circuit topology is shown in Fig. 2.

\section{THE IsSUE OF THE CONVENTIONAL PFM- CONTROLLED CURRENT-MODE RESONANT DC-DC CONVERTER IN MHZ LEVEL OPERATION}

To reduce the switching loss, the current-mode resonant DC-DC converter is widely used. Also, other researches have been proved using current-mode resonant DC-DC converter for high power-efficiency is very practical [16-19]. Generally, the current-mode resonant DCDC converter is controlled by PFM control which varies switching frequency. PFM control has been valid for the control of the resonant DC-DC converters in $\mathrm{kHz}$ level switching operation so far.

To show the static characteristics, the definitions of the converter are

$$
\begin{aligned}
& M=\left(2 n V_{o}\right) / V_{i}, \\
& \kappa=L_{m} / L_{r}, \\
& F=f_{s} / f_{0},
\end{aligned}
$$




$$
\begin{aligned}
& f_{0}=1 /\left(2 \pi \sqrt{L_{r} C_{r}}\right), \\
& \omega_{0}=2 \pi f_{0}, \\
& Q=Z_{0} / R_{a c}, \\
& R_{a c}=\left(8 n^{2} R_{L}\right) / \pi^{2} \\
& \text { and } \\
& Z_{0}=\sqrt{L_{r} / C_{r}}
\end{aligned}
$$

where turn ratio $n$, magnetizing inductance $L_{m}$, resonant inductance $L_{t}$, switching frequency $f_{s}$, resonant capacitance $C_{r}$ and load resistance $R_{L}$.

From literatures, voltage conversion ratio $M$ of PFMcontrolled current-mode resonant DC-DC converter is written by

$$
M=\frac{1}{\sqrt{\left(1+\frac{1}{\kappa}\left(1-\frac{1}{F^{2}}\right)\right)^{2}+Q^{2}\left(F-\frac{1}{F}\right)^{2}}}(11)
$$

From eq. (11), the static characteristics of PFM controlled current-mode resonant DC-DC converter can be leaded. Two examples of the static characteristics are shown in Fig. 3. One is $V_{i}=48 \mathrm{~V}, n=2.2, L_{m}=200 \mathrm{nH}, L_{r}$ $=100 \mathrm{nH}, C_{r}=10 \mathrm{nF}, Z_{0}=3.16, f_{0}=5.04 \mathrm{MHz}$ and $\kappa=2$. The other is $V_{i}=48 \mathrm{~V}, n=2.2, L_{m}=200 \mathrm{nH}, L_{r}=10 \mathrm{nH}, C_{r}$ $=80 \mathrm{nF}, Z_{0}=0.354, f_{0}=5.63 \mathrm{MHz}$ and $\kappa=20$.

It is assumed that input voltage range is from 42 to $53 \mathrm{~V}$ at $R_{L}=1.2 \Omega$ and $V_{o}=12 \mathrm{~V}$. In case of $L_{r}=100 \mathrm{nH}$, for realization of the range, $F$ is changed from 0.81 to $0.99\left(f_{s}\right.$ is changed from 4.06 to $\left.4.99 \mathrm{MHz}\right)$. In contrast, in case of $L_{r}=10 \mathrm{nH}$, for realization of the range, $F$ is changed from 0.38 to $0.92\left(f_{s}\right.$ is changed from 2.16 to 5.17MHz).

The difference between two parameters can be confirmed. If switching frequency changes widely for controlling output voltage, the large noise filter will be needed. Therefore, the DC-DC converter is prevented from downsizing by large noise filter. If switching frequency changes narrow for controlling output voltage, the large resonant inductance is needed for controlling.

As a result, in $\mathrm{MHz}$ level operation for the miniaturization of the DC-DC converter, it is shown that PFM control is hard to be designed.

\section{The Proposed PWM-CONTROLlEd CURRENT- MODE RESONANT DC-DC CONVERTER}

The proposed current-mode resonant DC-DC converter can be controlled at fixed switching frequency. In addition, for controlling output voltage, this method need not any additional components.

\section{A. The Circuit Topology}

The circuit topology is based on a half-bridge type current-mode resonant DC-DC converter as shown in Fig. 2. The primary-side is the half-bridge topology. $\mathrm{Q}_{1}$ and $\mathrm{Q}_{2}$ are driven in $50 \%$ duty ratio, alternatively. $C_{o s s} 1$ and $C_{\text {oss } 2}$ are parasitic capacitance of primary-side switches

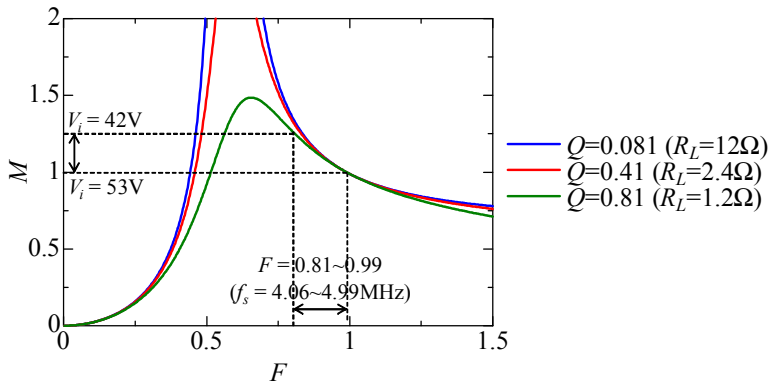

(a) $L_{r}=100 \mathrm{nH}, C_{r}=10 \mathrm{nF}, Z_{0}=3.16$.

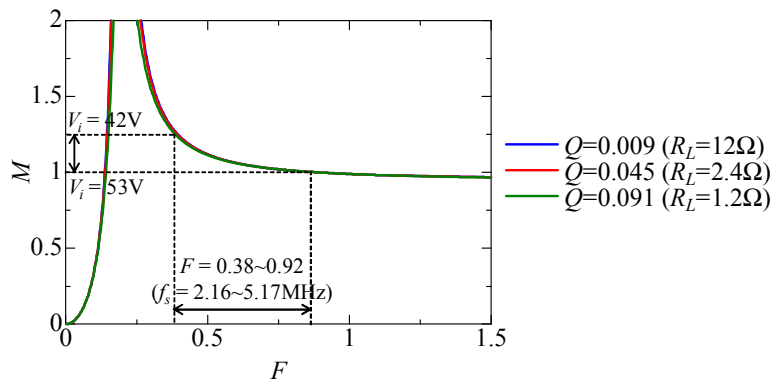

(b) $L_{r}=10 \mathrm{nH}, C_{r}=80 \mathrm{nF}, Z_{0}=0.354$.

Fig 3. The static characteristics of LLC resonant DC-DC converter with the conventional PFM control method.

$\mathrm{Q}_{1}$ and $\mathrm{Q}_{2} . C_{r 1}$ and $C_{r 2}$ are the resonant capacitors which have same capacitances and also make averaged voltage of $v_{c}$ to a half of the input. The inside of the broken line is the magnetic transformer which equivalently indicated that $L_{r}$ is leakage inductance, and $L_{m}$ is the transformer's magnetizing inductance. The turn ratio is $n: 1 . L_{r}$ is used as the resonant inductance. The secondary-side is the fullbridge topology composed with diodes $\mathrm{D}_{1}$ and $\mathrm{D}_{2}$ for high-side arm switches, and transistors $\mathrm{Q}_{3}$ and $\mathrm{Q}_{4}$ for low-side arm switches.

\section{B. The Principle of the Proposed PWM Control Method}

To simplify analysis of the circuit operation, the following assumptions are made:

- FETs are treated an ideal switch;

- The body diodes of the primary-side FET are neglected;

- The output capacitances of the primary-side FETs are constant during operation, satisfying $C_{o s s}=C_{o s s}, C_{o s s}=C_{o s s 1}+C_{o s s} 2$;

- Resonant capacitances are satisfied $C_{r 1}=C_{r 2}$, $C_{r}=C_{r 1}+C_{r 2}$;

- The forward voltage drop and the parasitic capacitance of the secondary-side diodes are neglected;

- The output capacitance and the body diodes of the secondary-side FETs are neglected;

- The output voltage is constant;

The output voltage can be controlled with changing the duty ratio of $\mathrm{Q}_{3}$ and $\mathrm{Q}_{4}$, simultaneously. When the duty ratio is less than 0.5 , the circuit is operated as well as conventional current resonance circuit. When the duty ratio is more than 0.5 , the circuit is operated in the proposed operation. 
The circuit can be separated into 5 states in the proposed operation with the switch combination as shown in TABLE I. The operational waveforms are shown in Fig. 4. The equivalent circuits for each state of a half switching term are shown in Fig. 5. In this figure, the switches drawn with weak colors represent OFF, and red line represents current flow. The definitions of the duty ratio $D$ is followed as

$$
\begin{aligned}
& D=T_{\text {on }} / T_{S}, \\
& D=1 / 2+D_{1}+D_{4}+D_{5}, \\
& D_{1}+D_{2}+D_{3}+D_{4}+D_{5}=1 / 2
\end{aligned}
$$

and

$$
\left\{\begin{array}{l}
D \leq 0.5 \cdots \cdots \cdots(\text { conventional operation }) \\
D>0.5 \cdots \cdots \cdots \cdot(\text { proposed operation })
\end{array}\right.
$$

where $T_{s}$ is the switching period, and $T_{o n}$ is the on-term of $\mathrm{Q}_{3}$ and $\mathrm{Q}_{4} . D_{1} \sim D_{5}$ are the duty ratio of the each state. The definitions of the resonant are followed;

$$
\begin{aligned}
& \omega_{1}=1 / \sqrt{\left(L_{r}+L_{m}\right) C_{r}}, \\
& Z_{1}=\sqrt{\left(L_{r}+L_{m}\right) / C_{r}}
\end{aligned}
$$

and

$$
\omega_{\text {oss }}=1 / \sqrt{L_{r} C_{\text {oss }}}
$$

The definitions of the initial value of the variable are followed;

$$
\begin{aligned}
& \qquad v_{c 1}(0)=V_{i} / 2-V_{c} \\
& \text { and } \\
& i_{r 1}(0)=I_{r}
\end{aligned}
$$

The description for each state is described below.

State $1\left(0<t<D_{1} T_{s}\right)$ :

In this state, $t_{1}$ is defined as $t_{1}=t$. The primary-side switch $\mathrm{Q}_{1}$ is turned $\mathrm{ON}$. Also, the secondary-side switch-
TABLE I. CIRCUIT OPERATION STATES

\begin{tabular}{|c|c|c|c|c|c|c|}
\hline \multirow{2}{*}{ State } & \multicolumn{4}{|c|}{ FET } & \multicolumn{2}{c|}{ Diode } \\
\cline { 2 - 7 } & $\mathrm{Q}_{1}$ & $\mathrm{Q}_{2}$ & $\mathrm{Q}_{3}$ & $\mathrm{Q}_{4}$ & $\mathrm{D}_{1}$ & $\mathrm{D}_{2}$ \\
\hline State 1 & ON & OFF & ON & ON & OFF & OFF \\
\hline State 2 & ON & OFF & ON & OFF & OFF & ON \\
\hline State 3 & ON & OFF & ON & OFF & OFF & OFF \\
\hline State 4 & ON & OFF & ON & ON & OFF & OFF \\
\hline State 5 & OFF & OFF & ON & ON & OFF & OFF \\
\hline
\end{tabular}

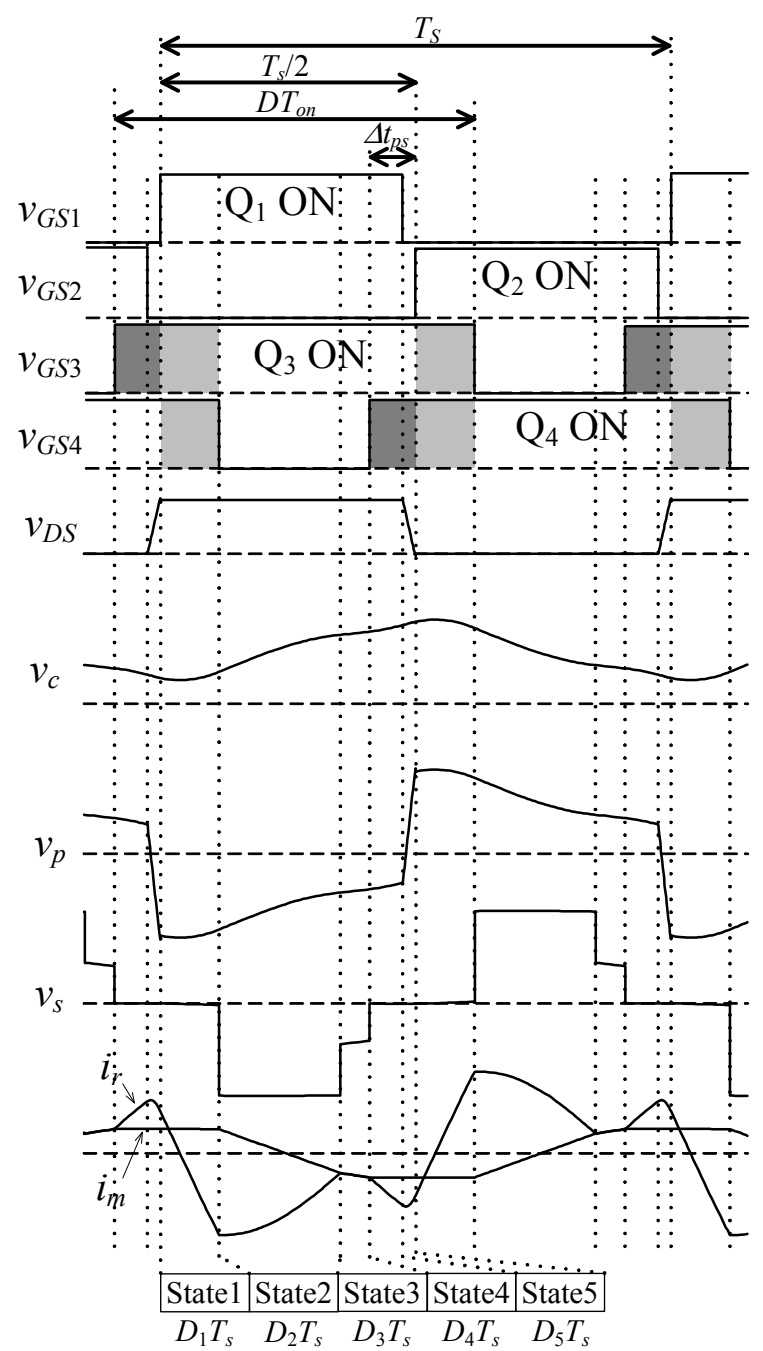

Fig. 4. The operational waveforms of the proposed PWM control.

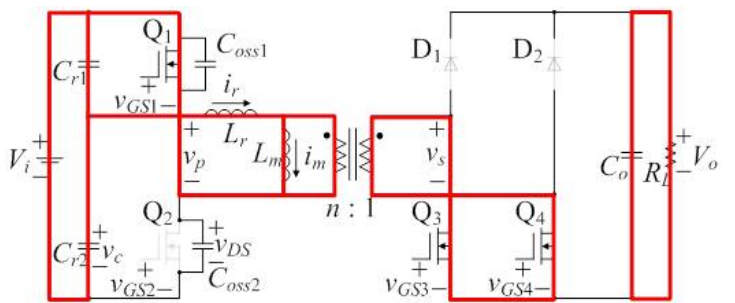

(a) State $1\left(0<t<D_{1} T_{s}\right)$

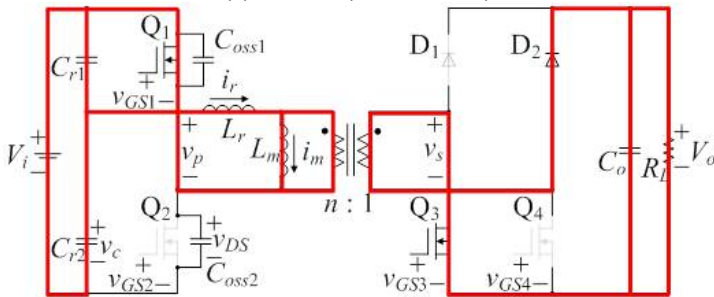

(b) State $2\left(D_{1} T_{s}<t<\left(D_{1}+D_{2}\right) T_{s}\right)$.

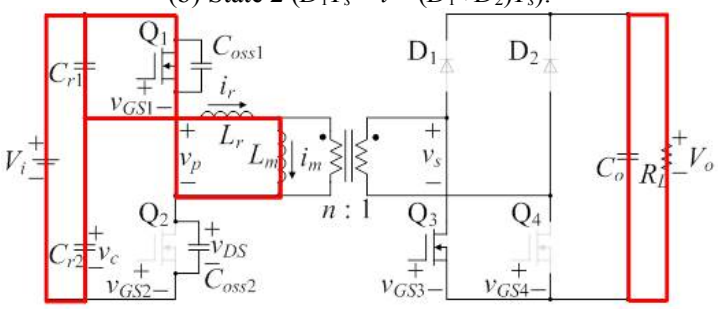

(c) State $3\left(\left(D_{1}+D_{2}\right) T_{s}<t<\left(D_{1}+D_{2}+D_{3}\right) T_{s}\right)$.

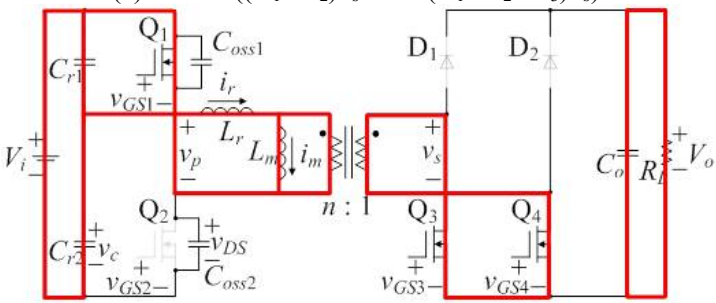

(d) State $4\left(\left(D_{1}+D_{2}+D_{3}\right) T_{s}<t<\left(D_{1}+D_{2}+D_{3}+D_{4}\right) T_{s}\right)$.

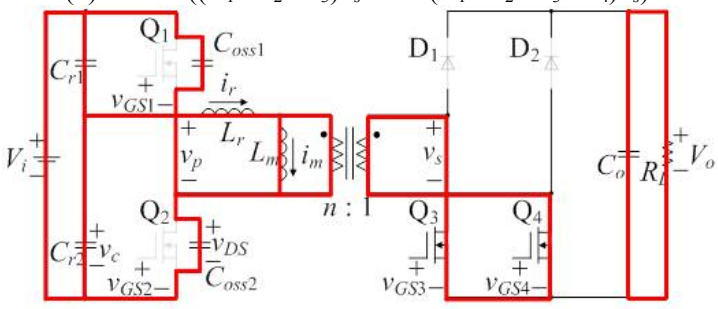

(e) State $5\left(\left(D_{1}+D_{2}+D_{3}+D_{4}\right) T_{s}<t<T_{s} / 2\right)$.

Fig. 5. The equivalent circuits for each state of the proposed PWM method. 
es both $\mathrm{Q}_{3}$ and $\mathrm{Q}_{4}$ are turned $\mathrm{ON} . \mathrm{Q}_{3}$ and $\mathrm{Q}_{4}$ are overlapped as indicated with the light gray area in Fig. 4 . The resonant inductance $L_{r}$ is magnetized by $i_{r}$ for boosting output voltage. From the figure, $V_{c 1}\left(t_{1}\right)$ and $i_{r 1}\left(t_{1}\right)$ are become

$$
v_{c 1}\left(t_{1}\right)=V_{i}-\left\{\left(V_{i} / 2+V_{c}\right) \cos \left(\omega_{0} t_{1}\right)+Z_{0} I_{r} \sin \left(\omega_{0} t_{1}\right)\right\}
$$

and

$$
i_{r 1}\left(t_{1}\right)=-1 / Z_{0}\left(V_{i} / 2+V_{c}\right) \sin \left(\omega_{0} t_{1}\right)+I_{r} \cos \left(\omega_{0} t_{1}\right) .
$$

The final values of the state 1 are

$$
\begin{gathered}
V_{c 2}=v_{c 1}\left(D_{1} T_{S}\right) \\
I_{r 2}=i_{r 1}\left(D_{1} T_{S}\right) .
\end{gathered}
$$

and

State $2\left(D_{1} T_{s}<t<\left(D_{1}+D_{2}\right) T_{s}\right)$ :

In this state, $t_{2}$ is defined as $t_{2}=t-D_{1} T_{s}$. After $\mathrm{Q}_{4}$ is turned OFF, the direction of the voltage applied to $\mathrm{D}_{2}$ is inverted, and diode of $\mathrm{D}_{2}$ becomes $\mathrm{ON}$. The inductance current which is magnetized in state 1 flow through diode $\mathrm{D}_{2}$ and switch $\mathrm{Q}_{3}$, to the load. From the figure, $v_{c 2}\left(t_{2}\right)$ and $i_{t 2}\left(t_{2}\right)$ are become

$$
\begin{aligned}
& v_{c 2}\left(t_{2}\right)=V_{i}-n V_{o} \\
& +\left(V_{c 2}-V_{i}+n V_{o}\right) \cos \left(\omega_{0} t_{2}\right)-Z_{0} I_{r 2} \sin \left(\omega_{0} t_{2}\right)
\end{aligned}
$$

and

$$
\begin{aligned}
& i_{r 2}\left(t_{2}\right)=1 / Z_{0}\left(V_{c 2}-V_{i}+n V_{o}\right) \sin \left(\omega_{0} t_{2}\right) \\
& +I_{r 2} \cos \left(\omega_{0} t_{2}\right)
\end{aligned}
$$

The final values of the state 2 are

$$
V_{c 3}=v_{c 2}\left(D_{2} T_{S}\right)
$$

and

$$
I_{r 3}=i_{r 2}\left(D_{2} T_{S}\right) .
$$

State $3\left(\left(D_{1}+D_{2}\right) T_{s}<t<\left(D_{1}+D_{2}+D_{3}\right) T_{s}\right)$ :

In this state, $t_{3}$ is defined as $t_{3}=t-D_{1} T_{s}-D_{2} T_{s}$. The direction of the diode $\mathrm{D}_{2}$ current is inverted, and diode of $\mathrm{D}_{2}$ becomes OFF. In the state, resonant current $i_{r}$ equal to magnetizing current $i_{m}$. From the figure, $v_{c 3}\left(t_{3}\right)$ and $i_{r 3}\left(t_{3}\right)$ are become

$$
v_{c 3}\left(t_{3}\right)=V_{i}+\left(V_{c 3}-V_{i}\right) \cos \left(\omega_{1} t_{3}\right)-Z_{1} I_{r 3} \sin \left(\omega_{1} t_{3}\right)
$$

and

$$
i_{r 3}\left(t_{3}\right)=1 / Z_{1}\left(V_{c 3}-V_{i}\right) \sin \left(\omega_{1} t_{3}\right)+I_{r 3} \cos \left(\omega_{1} t_{3}\right) .
$$

The final values of the state 3 are

$$
V_{c 4}=v_{c 3}\left(D_{3} T_{S}\right)
$$

and

$$
I_{r 4}=i_{r 3}\left(D_{3} T_{S}\right)
$$

State $4\left(\left(D_{1}+D_{2}+D_{3}\right) T_{s}<t<\left(D_{1}+D_{2}+D_{3}+D_{4}\right) T_{s}\right)$ :

In this state, $t_{4}$ is defined as $t_{4}=t-D_{1} T_{s}-D_{2} T_{s}-D_{3} T_{s}$. This state is similar to state 1 . In the state, the resonant inductance $L_{r}$ is magnetized by $i_{r}$ for primary-side ZVS turn on. $\mathrm{Q}_{3}$ and $\mathrm{Q}_{4}$ are overlapped as indicated with the dark gray area in Fig. 4. From the figure, $V_{c 4}\left(t_{4}\right)$ and $i_{r 4}\left(t_{4}\right)$ are become

$$
v_{c 4}\left(t_{4}\right)=V_{i}+\left(V_{c 4}-V_{i}\right) \cos \left(\omega_{0} t_{4}\right)-Z_{0} I_{r 4} \sin \left(\omega_{0} t_{4}\right)
$$

and

$$
i_{r 4}\left(t_{4}\right)=1 / Z_{0}\left(V_{c 4}-V_{i}\right) \sin \left(\omega_{0} t_{4}\right)+I_{r 4} \cos \left(\omega_{0} t_{4}\right)
$$

The final values of the state 4 are

$$
\begin{gathered}
V_{c 5}=v_{c 4}\left(D_{4} T_{S}\right) \\
I_{r 5}=i_{r 4}\left(D_{4} T_{S}\right) .
\end{gathered}
$$

and

State $5\left(\left(D_{1}+D_{2}+D_{3}+D_{4}\right) T_{s}<t<T / 2\right)$ :

In this state, $t_{5}$ is defined as $t_{5}=t-D_{1} T_{s}-D_{2} T_{s}-D_{3} T_{s}-D_{4} T_{s}$ The primary-side switch $\mathrm{Q}_{1}$ is turned OFF. All primaryside switches are turned OFF, called dead-time. The parasitic capacitor $C_{\text {oss }}$ of $\mathrm{Q}_{1}$ is discharged by a half of resonant inductance current $i_{r^{\prime}} \mathrm{Q}_{3}$ and $\mathrm{Q}_{4}$ are overlapped as indicated with the dark gray area in Fig. 4. From the figure, $V_{c 5}\left(t_{5}\right), V_{D S 5}\left(t_{5}\right)$ and $i_{r 5}\left(t_{5}\right)$ are become

$$
\begin{aligned}
& v_{c 5}\left(t_{5}\right)=V_{c 5}-\frac{\omega_{0}^{2}\left(V_{c 5}-V_{i}\right)}{\omega_{0}^{2}+\omega_{o s s}^{2}} \\
& +\frac{\omega_{0}{ }^{2}\left(V_{c 5}-V_{i}\right)}{\omega_{0}{ }^{2}+\omega_{o s s}{ }^{2}} \cos \left(\sqrt{\omega_{0}^{2}+\omega_{o s s}^{2}} \cdot t_{5}\right) \text {, } \\
& -\frac{I_{r 5}}{C_{r} \sqrt{\omega_{0}^{2}+\omega_{o s s}^{2}}} \sin \left(\sqrt{\omega_{0}^{2}+{\omega_{o s s}^{2}}^{2}} \cdot t_{5}\right) \\
& v_{D S 5}\left(t_{5}\right)=\frac{\omega_{o s s}{ }^{2}\left(V_{c 5}-V_{i}\right)}{\omega_{0}{ }^{2}+\omega_{o s s}{ }^{2}}+V_{i} \\
& -\frac{\omega_{o s s}{ }^{2}\left(V_{c 5}-V_{i}\right)}{\omega_{0}{ }^{2}+\omega_{o s s}{ }^{2}} \cos \left(\sqrt{\omega_{0}^{2}+\omega_{o s s}^{2}} \cdot t_{5}\right) \\
& +\frac{I_{r 5}}{C_{\text {oss }} \sqrt{\omega_{0}^{2}+\omega_{\text {oss }}^{2}}} \sin \left(\sqrt{\omega_{0}^{2}+\omega_{o s s}^{2}} \cdot t_{5}\right)
\end{aligned}
$$

and

$$
\begin{aligned}
& i_{r 5}\left(t_{5}\right)=\frac{V_{c 5}-V_{i}}{L_{r} \sqrt{\omega_{0}{ }^{2}+\omega_{o s s}^{2}}} \cdot \sin \left(\sqrt{\omega_{0}^{2}+\omega_{o s s}^{2}} \cdot t_{5}\right) \\
& +I_{r 5} \cos \left(\sqrt{\omega_{0}^{2}+\omega_{o s s}^{2}} \cdot t_{5}\right)
\end{aligned}
$$

\section{The Method for Achieving Primary-side ZVS Turn On in the Proposed PWM Control}

To accomplish the primary-side ZVS turn on, small magnetizing inductance $L_{m}$ have been used generally. However, small $L_{m}$ leads to increase of primary-side current which is cause of reducing power-efficiency. Therefore, to accomplish the ZVS operation in the proposed converter, phase-shift between primary and secondaryside switches which control resonant current is adopted. As shown in Fig. 4, the proposed operation has phase- 
shift between primary and secondary-side switches. $\Delta t_{p s}$ is the time length of the phase-shift. Without the phaseshift, $\Delta t_{p s}=0 \mathrm{~ns}$, the previous state of the dead-time becomes discontinuous current state. With this situation, initial current cannot be charged enough for ZVS because of secondary parasitic capacitance. Therefore, even with the long dead-time term, ZVS cannot be achieved. With the phase-shift, the problem of the initial current can be solved. From eqs. (34) and (36), the initial current of the dead-time, $I_{r 5}$ is

$$
I_{r 5}=1 / Z_{0}\left(V_{c 4}-V_{i}\right) \sin \left(\omega_{0} D_{4} T_{S}\right)+I_{r 4} \cos \left(\omega_{0} D_{4} T_{S}\right) .
$$

The term of the phase-shift becomes

$$
\Delta t_{p s}=D_{4} T_{S}+D_{5} T_{S} .
$$

In eq. (41), as defined as the $D_{5} T_{s}$ is fixed, the term of state 4 becomes larger with the increase of $\Delta t_{p s}$. $I_{r 5}$ is related to $\Delta t_{p s}$ almost linearly. With the enough amount of $I_{r 5}$, the amount of electrical charge $q_{r 5}$ which flows resonant inductance in dead-time becomes larger. For an example, in the conditions of $C_{\text {oss }}=900 \mathrm{pF}, V_{i}=36 \mathrm{~V}, R_{L}=$ $1.5 \mathrm{ohm}, D_{5} T_{s}=5 \mathrm{~ns}$, the relation of $\Delta t_{p s}$ and $q_{r 5}$ are shown in Fig. 6. The electrical charge $q_{r 5}$ can be calculated with

$$
q_{r 5}=\int_{0}^{D_{5} T_{S}} i_{r 5}(t) d t
$$

For achieving ZVS, $q_{r 5}$ has to be larger than the amount of the electrical charge of the parasitic capacitance of the switch as

$$
\left|q_{r 5}\right|>q_{\text {oss }}
$$

where $q_{\text {oss }}=C_{\text {oss }} V_{i}$

From the figure, it can be seen that the phase-shift $\Delta t_{p s}$ between primary and secondary-side switches are valid for ZVS operation for the proposed PWM control.

\section{The Advantage of the Proposed Method at $\mathrm{MHz}$ Level Operation}

Similar to section III, two examples of the static characteristics of the proposed PWM controlled currentmode resonant DC-DC converter are shown in Fig. 7.

It is assumed that input voltage range is from 42 to $53 \mathrm{~V}$ at $R_{L}=1.2 \Omega$ and $V_{o}=12 \mathrm{~V}$. In case of $L_{r}=100 \mathrm{nH}$, for realization of the range, $D$ is changed from 0.5 to 0.61 . In contrast, in case of $L_{r}=10 \mathrm{nH}$, for realization of the range, $D$ is changed from 0.5 to 0.55 . By comparing between two parameters, the case of $L_{r}=10 \mathrm{nH}$ can control in narrow duty ratio than the other one. Therefore, the proposed PWM control method is seem to be suitable for the miniaturization of the DC-DC converter because the output voltage can be controlled with small resonant inductance.

\section{EXPERIMENTAL RESULTS}

In this section, it can be confirmed the difference between the experimental results of the proposed method and the targets of the study.

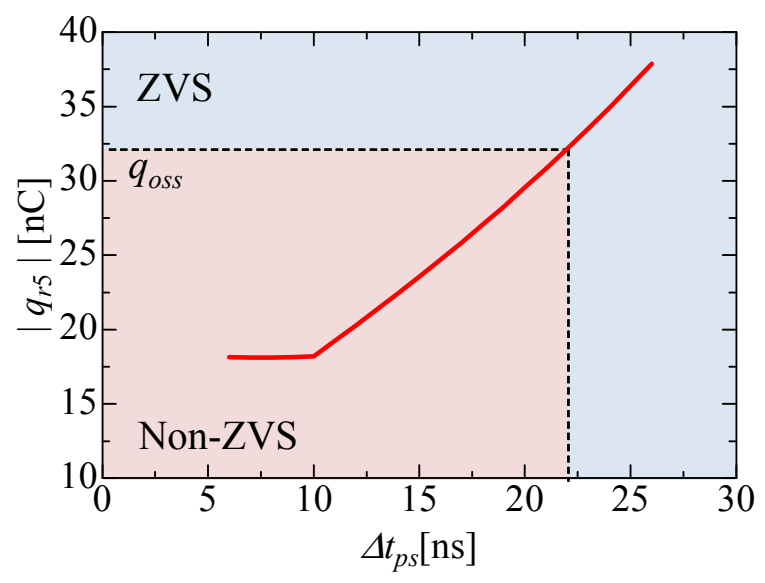

Fig 6. The effect of the phase-shift $\Delta t_{p s}$ vs $\left|q_{r 5}\right|$.

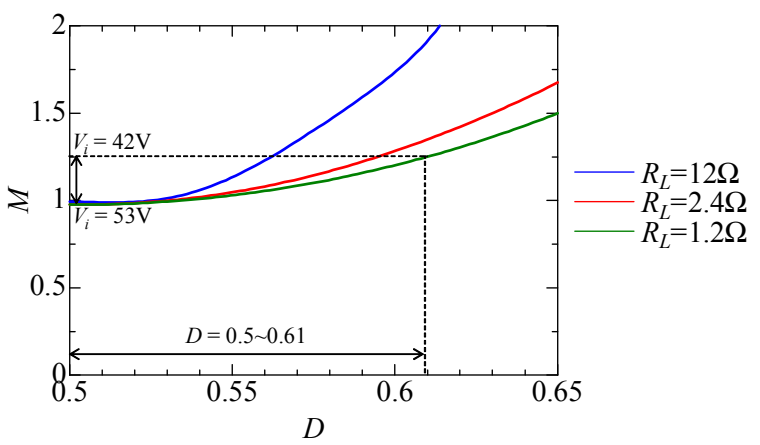

(a) $L_{r}=100 \mathrm{nH}, C_{r}=10 \mathrm{nF}, Z_{0}=3.16$.

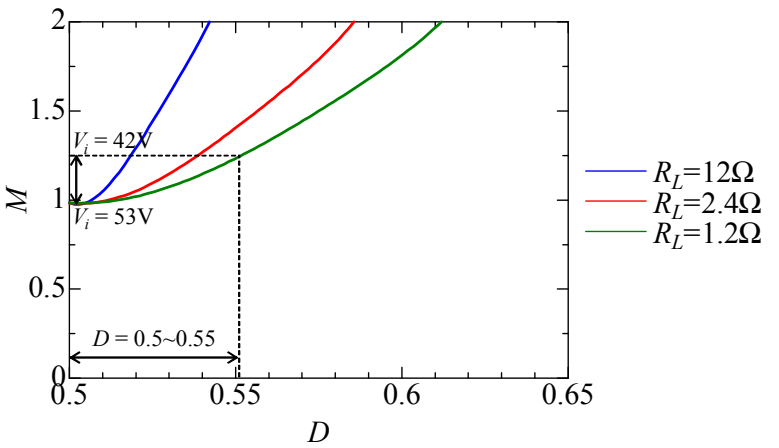

(b) $L_{r}=10 \mathrm{nH}, C_{r}=80 \mathrm{nF}, Z_{0}=0.354$.

Fig 7. The static characteristics of resonant DC-DC converter with the proposed PWM control method.

TABLE II. EXPERIMENTAL PARAMETERS

\begin{tabular}{c|c}
\hline Specifications & Value \\
\hline Output reference voltage: $V_{o}$ & $12 \mathrm{~V}$ \\
Transformer ratio $n: 1$ & $2: 1$ \\
Switching frequency: $f_{s}$ & $5 \mathrm{MHz}$ \\
Resonant frequency: $f_{r}$ & $4.98 \mathrm{MHz}$ \\
Transformer leakage inductance: $L_{r}$ & $33 \mathrm{nH}$ \\
Transformer magnetizing inductance: $L_{m}$ & $200 \mathrm{nH}$ \\
Resonant capacitor: $C_{r 1}, C_{r 2}$ & $15.5 \mathrm{nF}$ \\
Output capacitor: $C_{o}$ & $18.8 \mu \mathrm{F}$ \\
\hline
\end{tabular}

\section{A. The Experimental Conditions}

As a prototype digital controller, field programmable gate array (FPGA) Cyclone IV is used, which generates individual gate signal for each switch. The on-term of the gate signals are manually changed with software. The resolution of the gate signals is 1 nano second.

Some experiments have been carried out with parameters as shown in TABLE II, and $12 \mathrm{~V}$ of constant out- 
put voltage with open loop control. Components used in the experiment are shown in TABLE III.

The main circuit of the proposed PWM-controlled $5 \mathrm{MHz}$ DC-DC converter with GaN-FETs is shown in Fig 8. The total volume of the main circuit of the proposed $5 \mathrm{MHz}$ DC-DC converter is $16.14 \mathrm{~cm}^{3}$.

\section{B. The Performance of the Proposed Method}

The open loop static characteristics of the $5 \mathrm{MHz}$ PWM-controlled DC-DC converter are exhibited as shown in Fig. 9. From the figure, it can be seen that voltage transfer ratio $M$ is controlled by duty ratio $D$, and input voltage range can be achieved $36-44 \mathrm{~V}$. The difference between the performance of the proposed method and the targets can be confirmed. The reason is that the ideal transformer turn ratio $n$ is 2.2 , however, the actual $n$ is 2. Planar transformer cannot be changed $n$ easily because the winding is incorporate into the substrate.

The waveforms of $I_{o}=0.89 \mathrm{~A}$ and $I_{o}=6.3 \mathrm{~A}$ with the phase-shift are shown in Fig. 10. The blue bar of deadtime shows achieving primary-side ZVS turn on and $\Delta t_{p s}$ is effective for primary-side ZVS operation.

The power-efficiency of the DC-DC converter at $V_{o}=$ $12 \mathrm{~V}$ is shown in Fig. 11. The maximum power-efficiency is $89.4 \%$, and maximum load current is $8 \mathrm{~A}$ at $V_{i}=44 \mathrm{~V}$. Also, at low input voltage $44 \mathrm{~V}$ or $36 \mathrm{~V}$, it can be seen that the power-efficiency is relatively low, and maximum load current is low. The reason is that large duty ratio is needed at low input voltage and large output current. The large duty ratio leads to large peak current which is cause of power dissipation. ZVS operation has been confirmed in the range of the experimental conditions.

The temperature distribution of the DC-DC converter as shown in Fig. 12, has been taken of the breadboard at $V_{i}=44 \mathrm{~V}$ and $I_{o}=8 \mathrm{~A}$. From the results, the temperature of the secondary-side is still in high level. The reason is that large duty ratio leads to the hard-switching of secondary-side switches, and large conduction loss of diodes is happened. On the other hand, the primary-side temperature is relatively low because of achieving ZVS turn on. Therefore, in the future, the hard-switching of secondaryside switches will be improved.

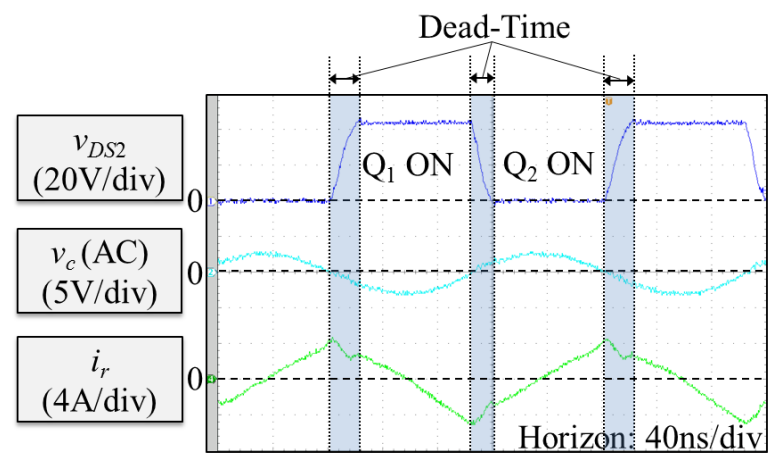

(a) $V_{i}=44 \mathrm{~V}, V_{o}=12 \mathrm{~V}, I_{o}=0.89 \mathrm{~A}, D=0.53, \Delta t_{p s}=3 \mathrm{~ns}$ $V_{i}=44 \mathrm{~V}, V_{o}=12 \mathrm{~V}, I_{o}=0.89 \mathrm{~A}, D=0.53, \Delta t_{p s}=3 \mathrm{~ns}$.
Fig. 10 . Experimental waveforms of resonant $\mathrm{DC}$-DC converter with the proposed PWM control method.
TABLE III. EXPERIMENTAL COMPONENTS

\begin{tabular}{c|c|c}
\hline Name & Manufacture & Part Name/ Material \\
\hline Primary side GaN-FET & EPC & EPC2001 \\
Secondary side & EPC & EPC2015 \\
GaN-FET & TEXAS & LM5113 \\
FET Driver & INSTRUMENTS & PDS1040L \\
Diode & DIODES & NiZn Ferrite Core \\
Transformer Core & TDK & C1608C0G1H392J \\
Material & TDK & C3216X7R1H105K \\
Resonant Capacitor & TDK & C2012X7R1E475M \\
Input Capacitor & TDK & DE0-nano \\
Output Capacitor & Terasic & (Cyclone IV) \\
FPGA & (ALTERA) & ISO722 \\
Isolator & TEXAS &
\end{tabular}

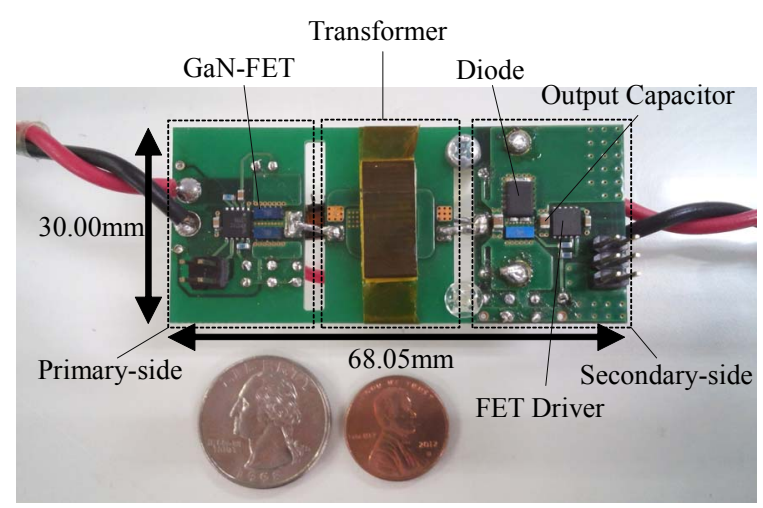

Fig. 8. The main circuit of the DC-DC converter.

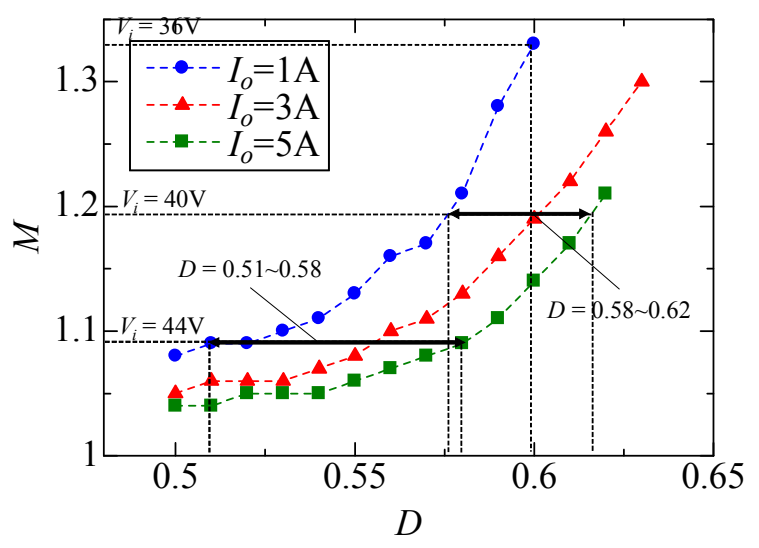

Fig. 9. The open loop static characteristics of resonant DC-DC converter with the proposed PWM control method.

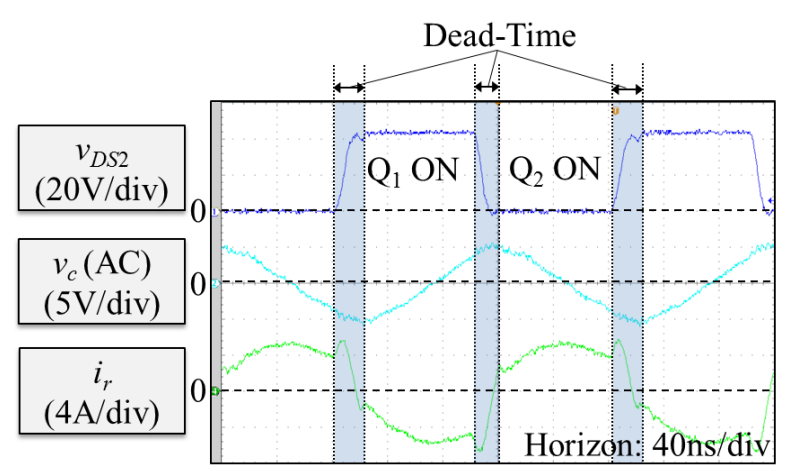
(a) $V_{i}=44 \mathrm{~V}, V_{o}=12 \mathrm{~V}, I_{o}=6.3 \mathrm{~A}, D=0.6, \Delta t_{p s}=13 \mathrm{~ns}$. 


\section{CONCLUSIONS}

In this paper, the method of the realization of a $\mathrm{MHz}$ level switching frequency DC-DC converter for high power-density is described. Furthermore, the novel PWM control method and achieving ZVS operation method for the current-mode resonant DC-DC converter in $\mathrm{MHz}$ level operation has been proposed.

The targets of the study is to obtain the high performance which is the small volume, $36-75 \mathrm{~V}$ or $42-53 \mathrm{~V}$ of input voltage range, $10 \mathrm{~A}$ of maximum load current range, the realization of primary-side ZVS turn on, and high power-efficiency.

Some experiments have been done with $5 \mathrm{MHz}$ isolated DC-DC converter which has GaN-FET, and the total volume of the circuit is $16.14 \mathrm{~cm}^{3}$. With the proposed PWM control method, input voltage range is $36-44 \mathrm{~V}$, and maximum load current range is $8 \mathrm{~A}$ at $44 \mathrm{~V}$. The primary-side ZVS turn on is confirmed, and the maximum powerefficiency is $89.4 \%$.

As the future work, to accomplish the targets of the study, detailed analysis of the proposed method with phase-shift, realization of the wide control range and feedback control by digital controller are under considerations.

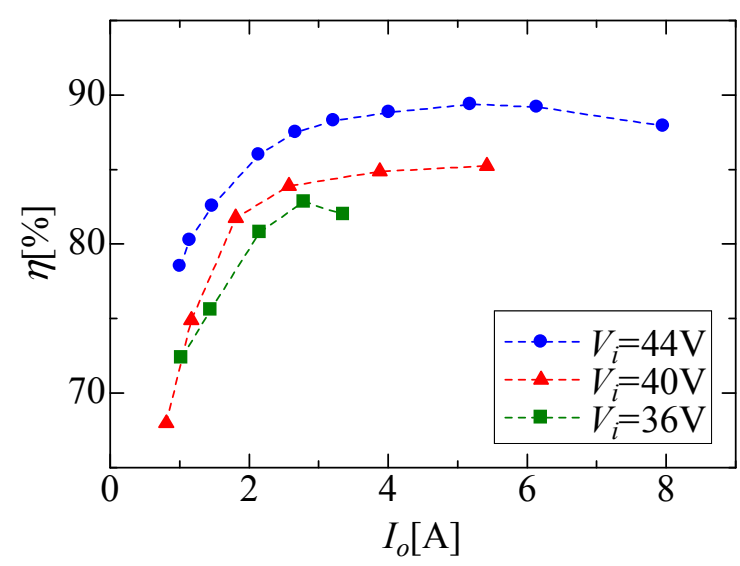

Fig. 11. The power-efficiency of resonant DC-DC converter with the proposed PWM control method at $V_{o}=12 \mathrm{~V}$.

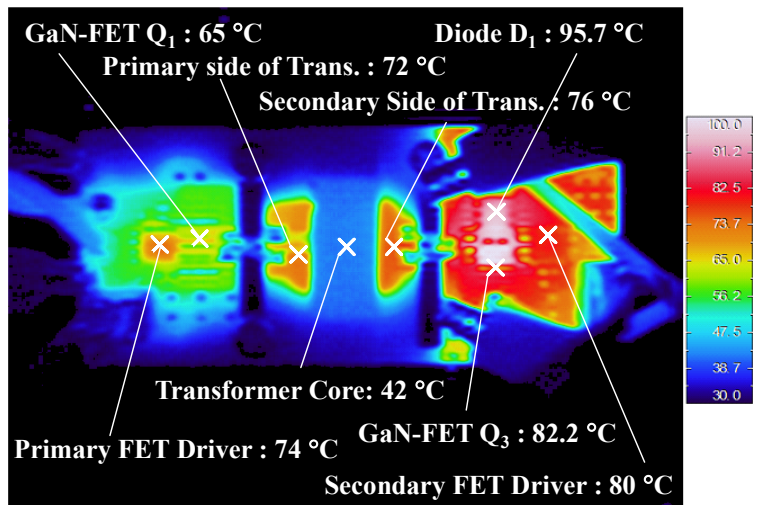

Fig. 12. The temperature distribution of resonant DC-DC converter with the proposed PWM control method at $V_{i}=44 \mathrm{~V}, V_{o}=12 \mathrm{~V}, I_{o}=8 \mathrm{~A}$.

\section{ACKNOWLEDGMENT}

The authors would like to thank Mr. Shohei Iwasaki of Nagasaki University Technical staff, for him technical support.

\section{REFERENCES}

[1] K. Matsuura, H. Yanagi, S. Tomioka and T. Ninomiya, "PowerDensity Development of a 5MHz-Switching DC-DC Converter," IEEE APEC 2012, pp.2326-2332.

[2] T. Zaitsu, T. Ninomiya, M. Shoyama, and H. Tanaka, "PWMControlled Current-Mode Resonant Converter Using an ActiveClamp Technique," IEEE PESC1996, pp.89-93.

[3] W. J. Lee, S. W. Choi, C. E. Kim, and G. W. Moon, "A New PWM-Controlled Quasi-Resonant Converter for a High Efficiency PDP Sustaining Power Module," IEEE Trans. Power Electron., vol. 23, no.4, 2008, pp.1782-1790.

[4] X. Xu, A. M. Khambadkone, T. M. Leong, and R. Oruganti, "A 1$\mathrm{MHz}$ Zero-Voltage-Switching Asymmetrical Half-Bridge DC/DC Converter: Analysis and Design," IEEE Trans. Power Electron., vol. 21, no. 1, 2006, pp. 105-113.

[5] Q. Li, M. Lim, J. Sun, A. Ball, Y. Ying, F. C. Lee, and K. D. T. Ngo, "Technology Road Map for High Frequency Integrated DCDC Converter," IEEE APEC 2010, pp. 533-539.

[6] N. Huapeng, P. Yunqing, Y. Xu, W. Laili, and W. Zhaoan, "Design of High Power Density DC Bus Converter Based on LLC Resonant Converter with Synchronous Rectifier," IEEE IPEMC 2009, pp. 540-543.

[7] Z. Gong, Q. Chen, X. Yang, B. Yuan, W. Feng, and Z. Wang, "Design of High Power Density DC-DC Converter Based on Embedded Passive Substrate," IEEE PESC 2008, pp. 273-277.

[8] S. Ji, D. Reusch and F. C. Lee, "High-Frequency High Power Density 3-D Integrated Gallium-Nitride-Based Point of Load Module Design," IEEE Trans. Power Electron., vol. 28, no. 9, 2013, pp.4216-4226.

[9] J. Delaine, P. O. Jeannin, D. Frey and K. Guepratte, "Improvement of $\mathrm{GaN}$ Transistors Working Conditions to Increase Efficiency of A 100W DC-DC Converter," IEEE APEC 2013, pp.656-663.

[10] Y. Wang, W. Kim, Z. Zhang, J. Calata, and K. D. T Ngo, "Experience with 1 to 3 Megahertz Power Conversion Using eGaN FETs," IEEE APEC 2013, pp.532-539.

[11] W. Zhang, Y. Long, Y. Cui, F. Wang, L. M. Tolbert, B. J. Blalock, S. Henning, J. Moses, and R. Dean, "Impact of Planner Transformer Winding Capacitance on Si-based and GaN-based LLC Resonant Converter,” IEEE APEC 2013, pp.1668-1674.

[12] W. Zhang, Y. Long, Z. Zhang, F. Wang, L. M. Tolbert, B. J. Blalock, S. Henning, C. Wilson, and R. Dean, "Evaluation and Comparison of Silicon and Gallium Nitride Power Transistors in LLC Resonant Converter," IEEE ECCE 2012, pp. 1362-1366.

[13] D. Reusch, and F. C. Lee, "High Frequency Isolated Bus Converter with Gallium Nitride Transistors and Integrated Transformer," IEEE ECCE 2012, pp. 3895-3902.

[14] Y. Xi, M. Chen, K. Nielson, and R. Bell, "Optimization of the Drive Circuit for Enhancement Mode Power GaN FETs in DC-DC Converters," IEEE APEC 2012, pp.2467-2471.

[15] " $5 \mathrm{~A}, 100 \mathrm{~V}$ Half-Bridge Gate Driver for Enhancement Mode GaN FETs," Texas Instruments Datasheet.

[16] C. Oeder, and T. Duerbaum, "ZVS Investigation of LLC Converters Based on FHA Assumptions," IEEE APEC 2013, pp. 2643-2648.

[17] R. L. Steigerwald, "A Comparison of Half-Bridge Resonant Converter Topologies," IEEE Trans. Power Electron., vol. 3, no. 2. 1988, pp. 174-182.

[18] S. Yang, M. Shoyama, and S. Abe, "Design of Low-Profile LLC Resonant Converter for Low Transformer Loss," IEEE TENCON 2010, pp. 1301-1306.

[19] B. Lu, W. Liu, Y. Liang, F. C. Lee, and J. D. Van Wyk, “Optimal Design Methodology for LLC Resonant Converter," IEEE APEC 2006, pp. 533-538. 